\title{
A decoração da Capela de São Miguel Arcanjo em São Miguel Paulista (SP)
}

THAIS CRISTINA MONTANARI ${ }^{I}$

\section{Introdução}

$\mathrm{O}$ S ESTUdOS que tratam da Capela de São Miguel Paulista sempre privilegiaram seus aspectos arquitetônicos e/ou a questão do restauro realizado pelo Iphan em 1939, muitas vezes sem contextualizar historicamente o monumento em sua gênese. Apesar de existirem muitos trabalhos sobre os aldeamentos jesuíticos - inerente à fundação da Capela -, esses estudos não costumam abordar as questões das artes e ofícios e de sua história dentro desse contexto peculiar. Assim, para melhor compreendermos o contexto histórico no qual se insere a Capela de São Miguel Arcanjo em sua gênese, retomamos a historiografia que trata dos aldeamentos e das Missões jesuíticas em São Paulo, bem como as documentações primárias, buscando compreender os atores sociais envolvidos no estabelecimento do aldeamento de São Miguel e a construção e ornamentação de sua capela.

A História da Arte como disciplina por muito tempo privilegiou um discurso pautado por uma visão formalista e eurocêntrica, transferindo tais visões e interpretações, especialmente ao se tratar da arte colonial brasileira. Tal abordagem não considera as especificidades locais, o contexto histórico-social, e tampouco as fontes documentais primárias, limitando-se, muitas vezes, apenas a aproximações de modelos tipológicos europeus. Ademais, aspectos considerados secundários, como os pigmentos, a mão de obra - sobretudo as indígena, negra e mestiça - e o conhecimento prévio desses artífices também são comumente desconsiderados ou tratados de forma superficial nesses estudos. Tendo isso em vista, propomos em nosso estudo um olhar decolonial, baseado em documentação primária, que adotasse uma perspectiva mais "global" a partir de uma perspectiva local para então compreender as relações interculturais promovidas pela grande circulação cultural fomentada pelos jesuítas no período colonial. Contudo, para isso, também consideramos e analisamos os debates historiográficos propostos pelas obras pioneiras, realizando revisões historiográficas sobre a arte e arquitetura coloniais na América. Desse modo, foi possível o aprofundamento dos estudos sobre a Capela de São Miguel Arcanjo, desenvolvendo, a partir da decoração da capela, um panorama das atividades artísticas no antigo aldeamento, analisando as trocas culturais entre as várias regiões da América Meridional. 


\section{Contexto histórico}

A história da Capela de São Miguel Arcanjo se inicia a partir do estabelecimento dos aldeamentos pelos padres da Companhia de Jesus nas imediações do Colégio Jesuítico de São Paulo, fundado em 1554. Esses aldeamentos, denominados como aldeias do Padroado Real ou aldeias de El-Rei, eram fixados sob um regime de tutoria, a partir de aldeias indígenas preexistentes na região. A fixação e a catequização dessas povoações indígenas faziam parte dos objetivos dos Regimes das Missões que estabeleceram os aldeamentos, buscando torná-los cada vez mais produtivos e eficazes, tornando-os núcleos de trabalho - sobretudo o agrícola - e de catequização. Inicialmente, confiaram-se quatro aldeias aos jesuítas em São Paulo: São Miguel, Pinheiros, Barueri e Guarulhos (Leite, 2000, p.227-30), as quais formavam uma rede de aldeamentos, conforme o avanço e o estabelecimento dos jesuítas na região. O principal objetivo evangelizador é indissociável dos aspectos políticos e econômicos. Afinal, a prosperidade dos empreendimentos da Companhia de Jesus supostamente garantiria sua permanência nas colônias.

Além das aldeias de El-Rei, os jesuítas também possuíram aldeamentos próprios, tendo novas fundações desde meados do século XVII. São elas: Carapicuíba, Mboy, Itapecerica, Itaquaquecetuba e São José (Rendon, 1978, p.38-9). Esses aldeamentos também eram chamados de fazendas jesuíticas, geralmente estabelecidas a partir de doações de particulares ao colégio. Todas essas administrações eram centradas no Colégio Jesuítico, que por sua vez atuava como um núcleo para as missões na região e atendia os padres e a comunidade com escola, igreja, biblioteca, oficinas e botica. Nas fazendas, os jesuítas detinham o poder espiritual e o temporal (Petrone, 1995, p.165). Por sua vez, nas aldeias do Padroado Real, apesar de os jesuítas possuírem o poder espiritual, a Câmara se fazia presente no poder temporal, especialmente a partir de 1640, quando os jesuítas foram expulsos de São Paulo.

A primeira expulsão dos jesuítas de São Paulo se deu em razão das disputas entre os colonos e os jesuítas em torno da questão da mão de obra indígena e a administração temporal dos aldeamentos. Além disso, o poder político e econômico dos jesuítas; as demandas dos jesuítas espanhóis contra as entradas dos paulistas nas missões do Paraguai; e até mesmo o suposto apoio dos padres ao sebastianismo em Portugal e a disseminação entre os indígenas serviram de pretexto e agravante para os descontentamento dos paulistas, resultando na expulsão dos padres da Companhia de Jesus no dia 13 de julho de 1640. Durante esse período em que os jesuítas estiveram proibidos de atuar em São Paulo, a administração temporal dos aldeamentos régios foram assumidos pela Câmara Municipal da Vila de São Paulo, e a administração espiritual foi assumida por padres seculares. Em 14 de maio de 1653, foi celebrado um acordo amigável entre os jesuítas, os paulistas e a Câmara de São Paulo, em que se explicitam as condições sob as quais os religiosos poderiam retornar. Assim, era acordado que os 
jesuítas desistissem de todas as queixas, ações, apelações contra os paulistas, bem como de qualquer indenização pelos danos sofridos pela expulsão; abdicar do breve papal de 1639 ou qualquer outro documento que defendesse a liberdade indígena; não recolher nem amparar os índios que fugissem dos moradores ou abrigá-los em suas fazendas e colégio (Leme, 1849, p.202-3; Leme, 1898, v.3, p.112-14; ACSP, v.6 p.24-6). Em contrapartida, os paulistas se comprometeram a ajudar na reforma do colégio, que foi realizada em 1671.

Foi nesse contexto que a Capela de São Miguel Arcanjo foi fundada, reconstruída e decorada. Consta da documentação que, antes mesmo de 1580, o aldeamento de São Miguel já possuía uma igreja, a qual era constantemente visitada pelos padres jesuítas do Colégio de São Paulo. Contudo, é bastante provável que essa igreja da fundação do aldeamento de São Miguel tenha sido construída de forma mais simples, e portanto não teria resistido por muito tempo, sendo necessária sua reconstrução, finalizada em 1622, conforme a inscrição na porta de entrada da capela.

Analisando a documentação primária, constatamos que os jesuítas atuaram de forma extraoficial e esporádica no aldeamento de São Miguel após a readmissão dos padres da Companhia de Jesus em 1653, possivelmente até a transferência do aldeamento para os cuidados dos franciscanos. Embora não seja possível estabelecer uma data precisa de quando ocorreu essa transferência, pela análise documental, estimamos que ela tenha ocorrido entre os anos 1701 e 1716.

\section{A Capela de São Miguel Arcanjo}

O fim da reconstrução da Capela de São Miguel data de 1622, período em que o aldeamento ainda era administrado pelos jesuítas do Colégio de São Paulo. Sua primitiva construção em taipa de pilão feita pelos indígenas do aldeamento sob a orientação atribuída ao padre João Álvares e ao carpinteiro espanhol Fernão Munhoz consistiu em uma capela arquitetonicamente diferente daquela que conhecemos hoje, que apresenta alguns acréscimos em sua construção. Conforme consta da documentação, no ano 1691, em razão dos aforamentos das terras dos indígenas de São Paulo, Diogo Barbosa do Rego requereu junto à Câmara de São Paulo o reparo das igrejas de São Miguel e de Nossa Senhora da Conceição de Guarulhos. Apesar de se tratar de uma possível primeira e grande reforma da Capela de São Miguel, não conhecemos mais nenhum documento que ateste quais obras teriam sido feitas nessa ocasião. Contudo, é bastante provável que a Capela de São Miguel tenha atingido seu "auge" de esplendor por volta de 1714, quando o rei Dom João V concedeu ornamentos para os altares laterais - muito provavelmente as pinturas parietais de nosso estudo - e um sino para Capela de São Miguel, requisitados pelos índios (Montanari, 2019, p.70).

Somente no período da administração do aldeamento pelos padres franciscanos teríamos o registro do que seria a mais expressiva reforma realizada na Capela de São Miguel, orientada por frei Mariano da Conceição Velloso, por volta de 1780. Nessa reforma, teriam sido feitos o arruamento do aldeamento 
e a "reedificação" da Capela, com o acréscimo de 2,5 metros de adobe sobre as paredes de taipa de pilão, elevando o pé direito da nave central de quatro para seis metros. Além disso, a abertura de duas janelas acima do telhado fronteiro, a construção dos altares laterais e o escoramento interno de madeira, a inserção de douramento no altar da sacristia e a construção da capela lateral, são atribuídas a essa reforma.

Muito difundida em São Paulo, a taipa foi usada em construções até o início do século XX. Contudo, seu uso em São Paulo é justificado indevidamente por parte da historiografia como expressão da pobreza paulista e seu isolamento que, segundo estudos mais recentes, não foi absoluto, mesmo nos séculos XVII e XVIII, antes da expansão do café pelo Estado. Mesmo assim, ao se tratar da Capela de São Miguel, os estudos de arte e arquitetura realizados até aqui destacam sua condição de "humildade" e "singeleza", se utilizando de expressões carregadas de pesar. Apenas sua construção em taipa, seu alpendre e sua talha da grade de comunhão eram dignos de nota. Mesmo o seu reconhecimento enquanto patrimônio nacional a ser preservado a nível federal pelo Iphan, no final da década de 1930, teria se dado muito mais pelo seu valor histórico do que pelo seu valor artístico e arquitetônico.

\section{Pinturas parietais}

A descoberta das pinturas parietais durante os trabalhos de restauro em 2007 surpreendeu a equipe de restauro e a comunidade acadêmica da área de história, arquitetura e história da arte. Tal surpresa se deu, especialmente, tanto pela sua peculiaridade plástica quanto pelo desconhecimento de sua existência, visto que essas permaneceram escondidas embaixo dos altares em madeira, provavelmente por algumas centenas de anos (Figura 1). Mesmo as reformas e restauros anteriores não atestaram a existência dessas pinturas, que tampouco foram atestadas pela bibliografia e documentação conhecida sobre a Capela de São Miguel Arcanjo. Ademais, não se conhecem exemplares de pinturas com tais especificidades e semelhanças nos templos religiosos paulistas que datam da mesma época. Além das pinturas parietais, durante o restauro também foram encontradas e recuperadas as pinturas do altar da capela lateral; além de vestígios de policromia na nave central e na sacristia, levantando a hipótese de que a Capela de São Miguel teria sido inteiramente pintada durante o período colonial.

Apesar da semelhança com os frescos portugueses do século XVII, na Capela de São Miguel Arcanjo, temos uma pintura "a seco", 1 sendo a parede de taipa o seu suporte. Diferentes estudiosos já enfatizaram, com efeito, a “simplicidade" e "ingenuidade" dessas pinturas. Contudo, seu valor plástico, formal e técnico deve ser reconhecido. É preciso termos em conta que essas pinturas têm pelo menos quatrocentos anos de existência, e foram descobertas em bom estado de preservação. Seus danos estão muito mais relacionados às condições ambientais, força mecânica dos altares em madeira, e intervenções na edificação, do que com a qualidade de seu suporte ou de seus pigmentos. 


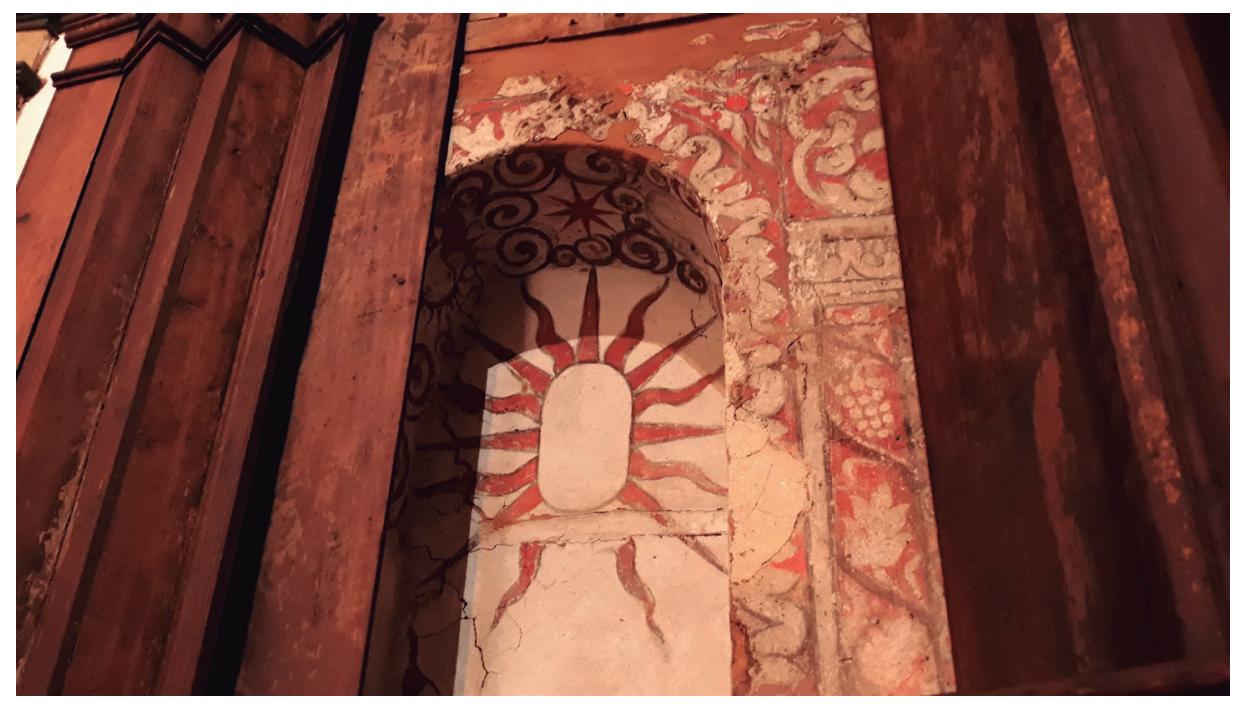

Figura 1 - Detalhe do camarim da pintura parietal do altar lateral do lado da epístola. Notar os desenhos de sol, lua, estrela e nuvens espirais no arco interno. Capela de São Miguel Arcanjo - São Miguel Paulista. São Paulo. Foto: Thais Montanari, abr. 2019.

O que torna as pinturas parietais da Capela de São Miguel Arcanjo tão singulares é o fato de simularem em pintura um retábulo de talha de um estilo do barroco português. Conhecido como estilo nacional-português (Smith, 1962, p.49-89); essa tipologia de retábulo apresenta colunas torsas, ornatos fitomórficos (folhagens e cachos de videiras), além dos capitéis com volutas. Em todo o espaço adjacente da pintura retabular, temos pinturas em padrões semelhantes a brutescos, ${ }^{2}$ predominando os desenhos em branco com contornos em preto sob o fundo em vermelho. Na parte interna do camarim e arco, temos pinturas de sol, lua, estrelas e nuvens espirais preenchendo os espaços adjacentes, além do sol como resplendor. Esse mesmo modelo retabular é predominante em outras igrejas paulistas do mesmo período, de gênese jesuítica - e também de outras ordens religiosas -, a exemplo dos retábulos laterais da igreja de Nossa Senhora do Rosário do Embu; os da antiga igreja do Pátio do Colégio dos Jesuítas em São Paulo; da igreja de Nossa Senhora da Conceição, a matriz de Itanhaém; e do antigo altar da fazenda Piraí, em Itú, hoje parte do acervo do Museu de Arte Sacra de São Paulo. Desse modo, se constata a predominância do modelo retabular de estilo nacional-português, muito provavelmente difundidos na região pela oficina do colégio jesuítico de São Paulo. Contudo, é preciso termos em conta que em todo o trecho superior das paredes, acima da altura das paredes em taipa em que se encontram as pinturas, onde deveríamos encontrar o coroamento da pintura retabular, temos todo um trecho de alvenaria de tijolos e adobes. ${ }^{3}$ Isso posto, malgrado as limitações que encontramos para a definição de um estilo e de uma datação precisa para essas pinturas, se não se trata de uma reprodução pintada de um retábulo em estilo nacional-português, podemos pelo menos 
afirmar se tratar de uma pintura de um retábulo de transição entre uma estruturação maneirista e ornamentação barroca ou de estilo nacional-português, em razão das colunas torsas.

A representação pintada sugerindo a ilusão de um altar fixo de talha é bastante recorrente em Portugal, denominados "retábulos fingidos", e também na Espanha, os "retablos simulados", entre os séculos XVI e XVIII. A mesma prática também foi recorrente na América hispânica, porém com suas devidas especificidades.

A presença da iconografia celeste de sol, lua e estrelas nas pinturas parietais da Capela de São Miguel Arcanjo pode tanto estar relacionada à correspondência simbólica de Cristo (o sol), de Nossa Senhora (a lua) e os santos (as estrelas) na arte euro-cristã, possivelmente retiradas de livros de emblemas como Mundus Symbolicus de Filippo Picinelli, cujo Livro I é dedicado ao tema dos astros; e também o livro La Philosophie des Images Enigmatiques (1694), do jesuíta Claude-François Menestrier (1631-1705), que possui um repertório de emblemas advindo, sobretudo, da cosmografia (Martins, 2019). Por outro lado, o emprego das imagens de constelações, do sol e da lua tornaria o trabalho de evangelização menos penoso, visto que essas imagens já seriam conhecidas e carregadas de significados para a cultura indígena, estabelecendo relações entre o imaginário católico e as crenças indígenas pré-coloniais (Plá, s. d., p.43).

A representação dos astros nas missões jesuíticas na América Espanhola, sobretudo na região dos Andes, foi estudada pela historiadora boliviana Teresa Gisbert em sua obra Iconografía y mitos indigenas en el arte. Gisbert demonstra que, diferentemente das outras ordens, os jesuítas teriam optado por uma representação racionalizada em que o Sol e as estrelas são criaturas sujeitas a um Deus criador (Gisbert, 2008, p.30). Esse tipo de relação em que o sol seria representado como um servo de Deus remontaria às tradições mais antigas dos povos indígenas (ibidem). Assim, de acordo com Gisbert, a representação do sol era uma das mais usadas nas decorações internas e externas das igrejas andinas, podendo frequentemente aparecer juntamente com as figuras de estrelas, lua e também sereias, como pode ser visto em portadas, retábulos, coberturas e abóbadas. Nas pinturas, essas imagens dos astros figuravam sobretudo na representação da Santíssima Trindade (ibidem). Isso posto, esses motivos celestes presentes nas pinturas parietais da Capela de São Miguel estariam mais ligadas a um duplo signo dessas imagens, do que a uma expressão indígena autóctone; contemplando, com efeito, tanto a cultura cristã europeia quanto as culturas ameríndias.

\section{Pigmentos}

De acordo com o relatório das análises laboratoriais dos pigmentos das pinturas parietais da Capela de São Miguel, concluiu-se que os pigmentos utilizados são derivados especialmente de material mineral, predominando o pigmento vermelho - uma mistura do vermelho de chumbo ( $\mathrm{Pb3O} 4)$ e do vermelhão $(\mathrm{HgS})$. A mesma mistura de pigmentos vermelhos também foram identificados 
nos altares de talha da igreja de Nossa Senhora do Rosário no Embu (São Paulo), além de outros pigmentos minerais (Schaefer, 2000, p.130-1). Desse modo, além da semelhante estrutura retabular de estilo nacional-português, os retábulos laterais da Igreja Nossa Senhora do Rosário e as pinturas parietais da Capela de São Miguel também possuem os mesmos pigmentos em sua decoração.

Assim como os símbolos celestes eram conhecidos e faziam parte da cosmologia indígena, notamos o mesmo tipo de conhecimento em relação aos pigmentos utilizados na decoração da Capela de São Miguel Arcanjo, dado seu coincidente uso nas capelas e igrejas da região da Ruta de la Plata que datam do mesmo período. Trata-se, portanto, de pigmentos previamente conhecido e utilizado pelos indígenas, além de carregar um forte valor simbólico em suas culturas. Antes mesmo da colonização, para os indígenas, esse derivado do cinábrio era utilizado nas pinturas murais e também corporais, e para a cultura indígena também seria portador de um poder sagrado, e assim como outros minérios era usado em cerimônias rituais de cura do corpo e da alma.

De acordo com Gabriela Siracusano (2005, p.107), cidades como Cuzco, Potosí e Charcas teriam sido os maiores centros provedores deste tipo de material até o início do século XVIII, evidenciando a circulação de pigmentos minerais e vegetais como resinas, óleos, auripigmento, vermelhão, pau-Brasil etc., entre as oficinas jesuíticas de Moxos e Chiquitos, onde esses pigmentos eram processados por aprendizes indígenas se utilizando de pedras ou tacanas (ibidem, p.157). Assim, é bastante provável que o pigmento vermelho usado na Capela de São Miguel, bem como na igreja de Nossa Senhora do Rosário no Embu, não fosse produzido localmente, visto que não existem jazidas de cinábrio no Brasil. Ademais, segundo Siracusano (2005), o uso do vermelhão combinado com o vermelho de chumbo indicaria que aqueles que decidiram por essa combinação - entre outras - dominavam a práxis e detinham conhecimento especializado, provavelmente advindo da leitura de manuais ou "livros de segredos", e pela troca oral e experimental entre os ofícios que também se utilizavam dessas "receitas". Essa mesma dinâmica pode ser notada ao se analisar os inventários dos Colégios Jesuíticos, conforme os estudos de Eliane Fleck e Roberto Poletto $(2015$, p.150), que apontaram a existência de uma considerável quantidade do vermelhão e do mercúrio em seu elemento puro, na Botica do Colégio Jesuítico de Córdoba, na Argentina. Dessa forma, levantamos a hipótese de que os Colégios Jesuíticos podem ter sido receptores desse tipo de material, proveniente da América hispânica, difundindo o uso deste pigmento pela vila de São Paulo.

Dois estudos publicados em 2018, envolvendo profissionais de diferentes áreas do conhecimento e de diferentes Universidades de Bolívia, Chile e Argentina, analisaram os pigmentos de pinturas murais das igrejas da antiga Ruta de la Plata. O primeiro estudo, "Raman Identification of Pigments in Wall Paintings of the Colonial Period from Bolivian Churches in the Ruta De La Plata. Conservation Science in Cultural Heritage" (Rúa, 2018, p.117-37.), analisou 
pigmentos de quatro igrejas bolivianas dos séculos XVII e XVIII: Curahuara de Carangas, Nuestra Señora de Copacabana de Andamarca, San José de Soracachi, e a sacristia da igreja de Santiago de Callapa. No caso das três primeiras igrejas, o vermelhão $(\mathrm{HgS})$ foi identificado para os pigmentos vermelhos. O segundo estudo, "Characterization of pigments and binders in a mural painting from the Andean church of San Andrés de Pachama (northernmost of Chile)" (Tomasini et al., 2018), analisou os pigmentos da igreja de San Andrés de Pachama (século XVIII), na região de Arica-Parinacota, no Chile, e também concluiu que os pigmentos vermelhos dessa igreja seriam o vermelhão. Esse estudo ainda indica as possíveis fontes de cinábrio de onde se teriam extraído para a produção desses pigmentos: as Minas de Huancavelica, no Peru, as quais já estariam esgotadas no século XVIII, porém podendo também se tratar de outras minas de regiões próximas, como Guamanda, no Peru, e das montanhas de Quíndio, na Colômbia, que também foram exploradas nesse período.

A difusão do uso do vermelhão, identificado nas pinturas da Capela de São Miguel, e também nas pinturas murais das capelas da Ruta de la Plata, evidencia a dimensão das trocas culturais naquele período, podendo se estabelecer uma rede entre as duas Américas coloniais. Essa mesma rede seria reforçada pelo comércio entre São Paulo e Paraguai, por meio dos caminhos terrestres ou pelo Atlântico até os portos de Assunção e de Buenos Aires; além da circulação de colonos, indígenas e missionários, que traziam consigo objetos, medicamentos, livros e conhecimento científico. As diversas semelhanças constatadas entre a decoração Capela de São Miguel e de algumas capelas e igrejas da América hispânica e da Europa - tais como o repertório iconográfico do sol, lua e estrelas provenientes de livros de emblemas; o repertório de brutescos e grotescas; a estrutura retabular de estilo nacional-português; o uso do vermelhão; e o uso de mão de obra indígena e mestiça -; podem demonstrar que São Paulo, ao menos artisticamente, não se encontrava isolada no Planalto.

\section{Repertório europeu, mão de obra local}

Além das pinturas murais, a decoração da Capela de São Miguel também apresenta os repertórios de brutescos e grotescas europeias, porém com a especificidade da mão de obra local. Contudo, não se trata de uma reprodução mecânica e irrefletida de um modelo por artífices locais, e tampouco de uma expressão indígena autóctone. Trata-se de como esses artífices reinterpretaram e (re)produziram esses modelos, de modo a dar forma a uma arte transculturada.

$\mathrm{Na}$ Capela de São Miguel Arcanjo, a utilização da mão de obra indígena, africana ou mestiça teria se dado na construção da capela e muito provavelmente, também na decoração. Além das pinturas parietais, é possível se notar o trabalho de artífices locais em outros elementos artísticos e decorativos da Capela, datados dos séculos XVII e XVIII e ainda hoje preservados. Apesar de termos algumas peças evidentemente um pouco mais eruditas - importadas da Europa -, grande parte delas ainda assim seriam, provavelmente, fruto da mão de obra local. As- 
sim, na Capela de São Miguel, além das pinturas parietais, ainda se destacam: as imagens; a pia batismal; o armário e o altar da sacristia; o altar da capela lateral, além das pinturas do forro e da grade de comunhão em jacarandá (Figura 2).

A grade de comunhão da Capela de São Miguel Paulista é provavelmente a peça que mais evidencia a mão de obra indígena ou mestiça. A peça em jacarandá apresenta em destaque duas figuras cariátides nas extremidades da banca, talhadas e com vestígios de policromia. Trata-se de duas figuras aparentemente femininas que se misturam com elementos fitomórficos em seu corpo e base. As peças não são idênticas, o que pode evidenciar se tratar de dois artífices diferentes, embora ambos pudessem ter o mesmo nível de habilidade técnica. A face, em ambas as figuras, é a parte que recebeu maior atenção do artífice, atento sobretudo ao desenho do nariz e boca. Essas figuras costumam gerar uma certa curiosidade, e receberam a atenção de Mário de Andrade em sua primeira visita técnica a serviço do Iphan, sendo a única peça fotografada na ocasião (Andrade, 1981, p.77). Também Lúcio Costa (2010, p.159), em seu estudo sobre a arquitetura dos jesuítas no Brasil, afirma que essas seriam "das mais antigas e autênticas expressões conhecidas de arte 'brasileira', em contraposição à maior parte das obras luso-brasileiras dessa época, que se deveriam melhor dizer 'portuguesas do Brasil'". É preciso termos em conta que, apesar da provável mão de obra indígena empregada na sua fatura, os modelos dessas cariátides, assim como as pinturas e os entalhes presentes nos batentes das portas e janelas da Capela de São Miguel, seriam derivados do repertório das grotescas europeias, ${ }^{4}$ expressando, por sua vez, a troca entre o mundo indígena/mestiço e o mundo europeu.

$\mathrm{Na}$ altar lateral da Capela de São Miguel, temos as pinturas do teto apresentando um repertório derivado dos brutescos (Figura 3). No restauro mais recente encontraram-se vestígios dessas pinturas em todo o altar. Contudo, pelo péssimo estado de preservação causado pelo uso indevido de óleo queimado, além de fatores ambientais, não foi possível recuperá-las em sua totalidade. $\mathrm{O}$ mesmo estilo e as cores também podem ser vistos - porém de forma mais erudita - na sacristia e no altar-mor da igreja de Nossa Senhora do Rosário do Embu; na pintura do teto da nave e da sacristia da Capela de Santo Antônio, e no forro da desaparecida capela do sítio Querubim, ambas em São Roque, interior de São Paulo. Além de poderem ser igualmente observados na ornamentação do armário da sacristia, da Capela de São Miguel (Figura 4), assim como nos armários da sacristia da Capela de Carapicuíba, no armário da sacristia da igreja de Nossa Senhora da Escada de Guararema, e também na tábua pintada do altar da igreja de Caçapava Velha (São Paulo) (Etzel, 1974, p.140). Além de serem obras que datam entre fins do século XVII e início do século XVIII, são capelas pertencentes a antigos núcleos de aldeamentos jesuíticos. Ademais, o mesmo estilo pictórico também está presente nas igrejas da Ruta de la Plata, da Espanha e de Portugal, como complementos de áreas adjacentes, a exemplo da igreja de Pitumarca, no Peru e a da ermida de Belén, em Liétor, na Espanha, cujas pinturas datam do século XVIII. Evidenciamos, portanto, a complexidade 


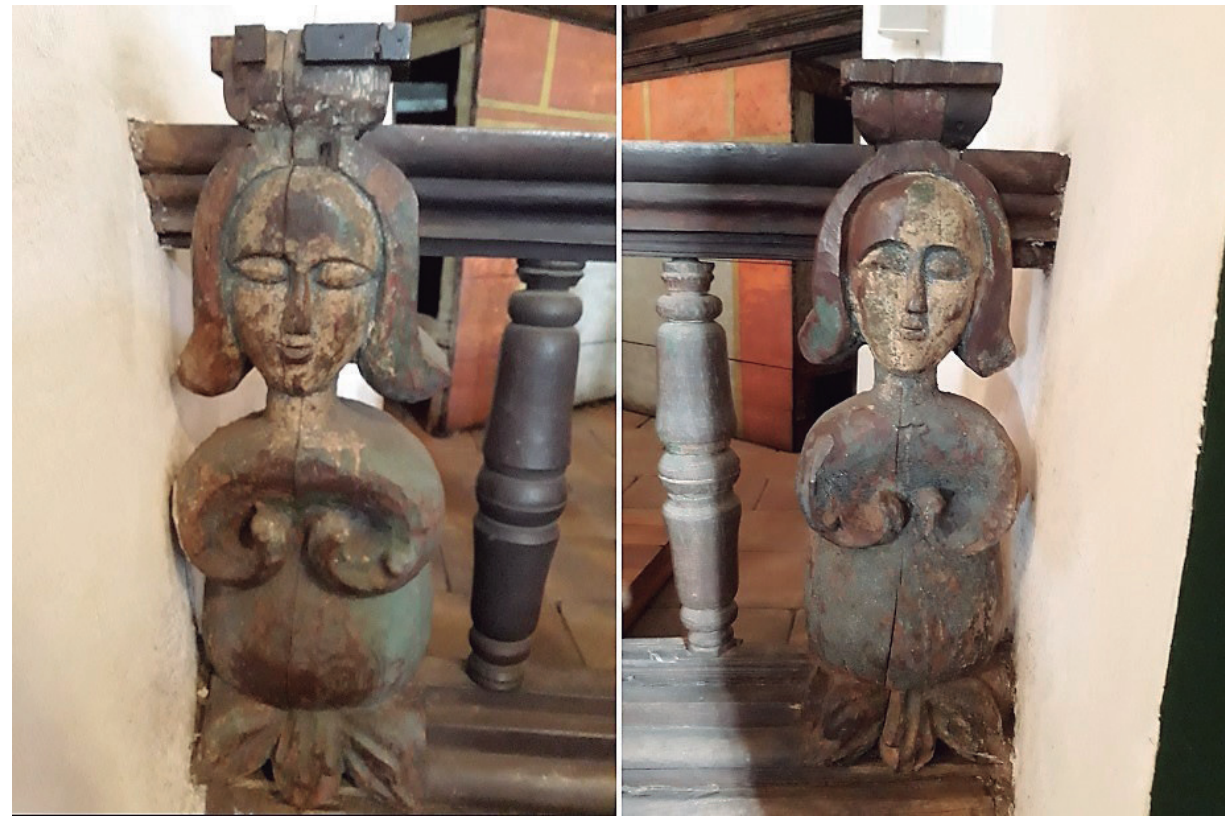

Figura 2 - Cariátides da grade de comunhão. Entalhadas em jacarandá e com vestígio de policromia. Capela de São Miguel Arcanjo - São Miguel Paulista. São Paulo. Foto: Thais Montanari, dez. 2017.

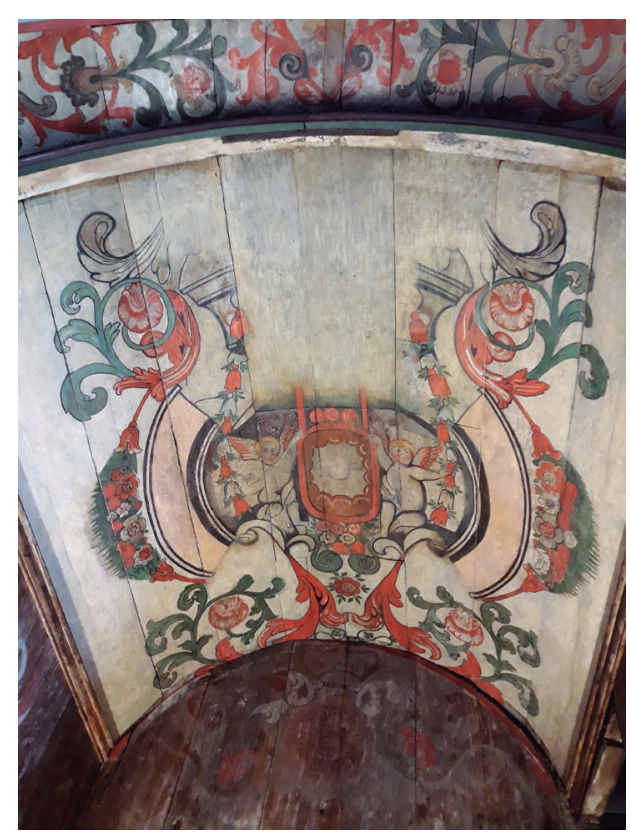

Figura 3 - Altar da capela lateral da Capela de São Miguel Arcanjo. Notar os vestígios de pintura entre o teto e a estrutura (esquerda). Capela de São Miguel Arcanjo - São Miguel Paulista. São Paulo. Foto: Thais Montanari. dez. 2017. 


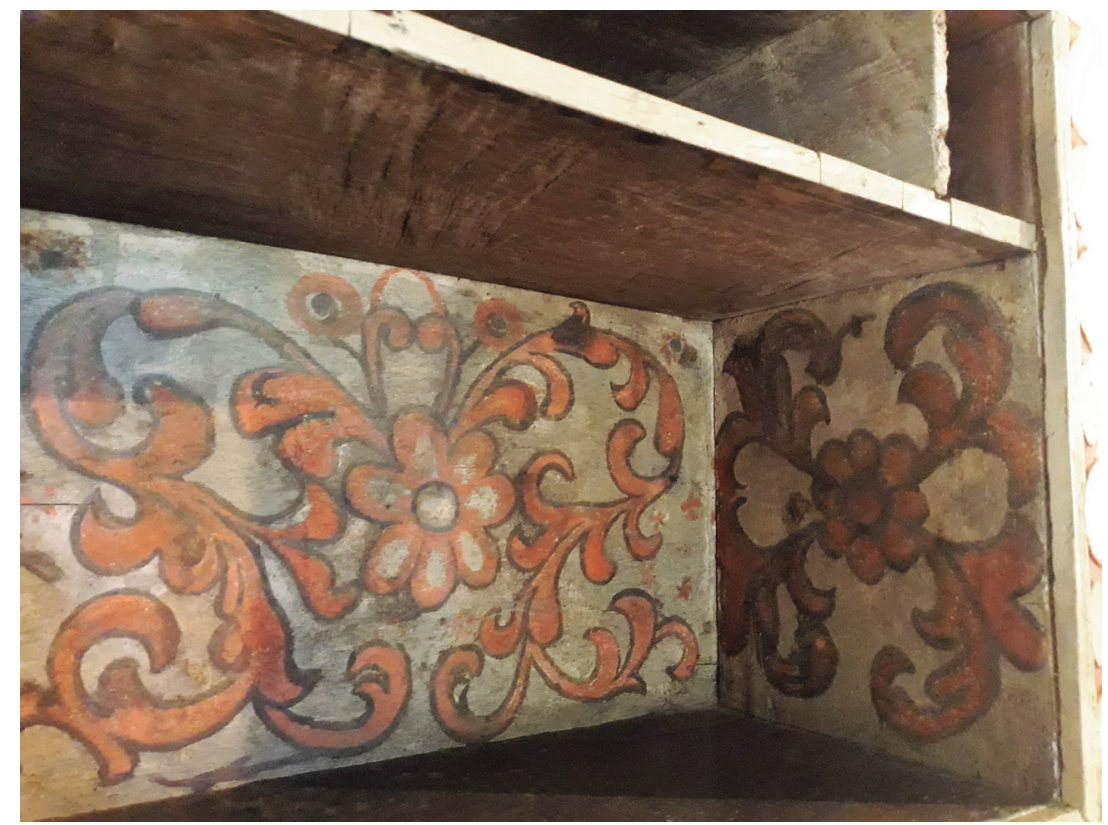

Figura 4 - Armário da sacristia da Capela de São Miguel Arcanjo. Capela de São Miguel Arcanjo - São Miguel Paulista. São Paulo. Foto: Thais Montanari. dez. 2017.

e a grande dimensão das trocas culturais que permearam entre Europa, América Hispânica e América Portuguesa, expressas na decoração de uma pequena capela de taipa localizada na zona leste da cidade de São Paulo.

\section{Considerações finais}

Os aldeamentos paulistas concentraram mão de obra indígena, que, por sua vez, se fez presente nos serviços públicos e a particulares. Ao mesmo tempo, os indígenas aldeados também trabalharam para a manutenção de seu próprio ambiente de vivência, sendo a construção e ornamentação da capela igualmente um dever da população desses assentamentos. É possível constatar na documentação o quanto a capela era importante para os indígenas cristãos que buscavam assistência espiritual.

Grande parte dos elementos decorativos da capela seria resultante de uma relação mediadora entre as culturas europeia e ameríndia por serem obras realizadas dentro de um contexto específico como o dos aldeamentos indígena-jesuíticos. As pinturas parietais evidenciam as possíveis relações entre São Paulo e a América hispânica, para além da União das Coroas Ibéricas (1580-1640). A dimensão dessas trocas culturais se evidencia pela difusão do uso do vermelhão identificado nas pinturas da Capela de São Miguel, e também nas pinturas murais das capelas da América hispânica da Ruta de la Plata, podendo se estabelecer uma rede entre as duas Américas coloniais. Essa mesma rede seria reforçada pelo comércio entre São Paulo e Paraguai, por meio dos caminhos terrestres ou pelo Atlântico até os portos de Assunção e de Buenos Aires; além da circulação 
de colonos, indígenas e missionários, que traziam consigo objetos, medicamentos, livros e conhecimento científico. As diversas semelhanças constatadas entre a decoração Capela de São Miguel e de algumas capelas e igrejas da América Hispânica e da Europa - tais como o repertório iconográfico do sol, lua e estrelas provenientes de livros de emblemas; o repertório de brutescos e grotescas; a estrutura retabular de estilo nacional-português; e o uso de mão de obra indígena e mestiça -; podem demonstrar que São Paulo, ao menos artisticamente, não se encontrava isolada no Planalto.

As pinturas parietais da Capela de São Miguel Arcanjo, por se tratar de obras necessariamente realizadas in loco - diferentemente, por exemplo, de uma obra de talha que poderia ser realizada em um local e transferida para outro -, são obras praticamente intocadas e preservam um modelo e iconografia tal qual havia sido pensado nas últimas décadas do século XVII. Por meio delas foi possível demonstrar e analisar a dimensão das diversas redes de trocas culturais entre as culturas europeia e ameríndia pelo uso da mão de obra local (indígena, mestiça, negra); por meio de um repertório estilístico e iconográfico europeu, reinterpretado pelos indígenas; e pelo uso de pigmentos importados e sofisticados. Essas pinturas ressignificam a história do aldeamento e da Capela de São Miguel, bem como a história de São Paulo, ao questionar as construções históricas e o apagamento das culturas indígenas e mestiças; e se apresentam como um importante documento para a nossa compreensão histórica e artística, rompendo com uma visão tradicional, eurocêntrica e formalista.

\section{Notas}

1 Geralmente, e muito provavelmente, usada na Capela de São Miguel Arcanjo, a técnica da têmpera. Na têmpera os pigmentos são misturados a um aglutinante, podendo ser gema de ovo, uma mistura de ovo inteiro e óleo, ou caseína, em uma emulsão de água. Atualmente também existem opções sintéticas como a têmpera acrílica e a têmpera vinílica.

2 A pintura de brutesco se baseia numa composição de uma sequência de formas vegetalizadas, geralmente folhas de acanto enroladas ou delgadas, a partir de um elemento central, podendo ter a ocorrência de flores, festões, mascarões ou outros elementos zoomorfos de forma harmônica e simétrica.

3 Possivelmente acrescido na reforma empreendida pelo Instituto Histórico e Geográfico de São Paulo em 1926, em que foi realizado um encamisamento de tijolos de alvenaria por toda a nave. As consequências da execução dessa reforma, chamada por eles de obra de "Restituição", foram constatadas anos mais tarde, no restauro coordenado por Luis Saia, que encontrará diversos problemas decorrentes desta reforma.

4 De acordo com Serge Gruzinski (2001, p.193), o repertório dos grotescos italianos teria se disseminado por toda a Europa, sobretudo na Península Ibérica, privilegiando as metamorfoses e hibridações presentes no pensamento do Renascimento. Por conseguinte, este repertório chegou e se disseminou nas Américas no período colonial pelos missionários em seus processos de evangelização. Em contato com o mundo indígena, a hibridação deu lugar à mestiçagem, nos termos do autor. 
Referências

ALMEIDA, M. R. C. de. Metamorfoses indigenas: identidade e cultura nas aldeias coloniais do Rio de Janeiro. Rio de Janeiro: Arquivo Nacional, 2003.

AMARAL, A. A. A Hispanidade em São Paulo: da casa rural à Capela de Santo Antônio. São Paulo: Nobel; Edusp, 1981.

ANDRADE, M. de. Mário de Andrade: cartas de trabalbo: correspondência com Rodrigo Mello Franco de Andrade (1936-1945). Rio de Janeiro: MEC; Sphan, 1981.

ARQUIVO PÚBLICO DO ESTADO DE SÃO PAULO. Documentos interessantes para a história e costumes de São Paulo. São Paulo: Imprensa Oficial, 1903. v.43.

ATAS DA CÂMARA DA VILA DE SÃO PAULO. São Paulo: Publicação da Divisão do Arquivo Histórico, 1914-1915. v.6.

BAILEY, G. A. Art of Colonial Latin America. London: Phaidon, 2005.

BELMONTE. No tempo dos bandeirantes. 3.ed. São Paulo: Melhoramentos, [19--].

CAETANO, J. I. Retábulos fingidos na pintura mural portuguesa. Lisboa: o autor, 2016. p.1. Disponível em: <https://www.academia.edu/21697216/Ret\%C3\%Albulos_fingidos_na_pintura_mural_portuguesa_vers\%C3\%A3o_n\%C3\%A3o_publicada_com_todas_as_imagens_dos_ret\%C3\%Albulos_referidos>. Acesso em: 2 abr. 2018.

COHEN-APONTE, A. Heaven, Hell, and Everything in Between. Murals of the Colonial Andes. Austin: University of Texas Press, 2016.

CORTI, P.; GUZMÁN, F.; PEREIRA, M. La Pintura Mural de Parinacota en el Último Bofedal de la Ruta de la Plata. Arica: Edición de Fundación Altiplano Monseñor Salas Valdés y Centro de Estudios del Patrimonio Universidad Adolfo Ibañez, 2013.

COSTA, L. A arquitetura dos jesuítas no Brasil. ARS (São Paulo) [online], v.8, n.16, p.127-95, 2010. Disponível em: <http://dx.doi.org/10.1590/S1678$53202010000200009>$. [Texto originalmente publicado na Revista do Serviço do Patrimônio Histórico e Artístico Nacional, Rio de Janeiro, n.5, p.105-169, 1941.]

DIVISÃO DO ARQUIVO HISTÓRICO DO DEPARTAMENTO DE CULTURA DA PREFEITURA DO MUNICÍPIO DE SÃO PAUlO. Atas da Câmara da Vila de São Paulo [ACSP], v.6; São Paulo: Publicação da Divisão do Arquivo Histórico, 1914-1915.

ETZEL, E. O Barroco no Brasil: psicologia - remanescentes em São Paulo, Goiás, Mato Grosso, Paraná, Santa Catarina, Rio Grande do Sul. 2.ed. São Paulo: Melhoramentos, 1974.

FERNANDES, E. Futuros outros: homens e espaços: os aldeamentos jesuíticos e a colonização na América portuguesa. Rio de Janeiro: Contra Capa. 2015.

FLECK, E. C. D.; POLETTO, R. Os colégios e boticas da Companhia de Jesus como centros de formação intelectual e de difusão da cultura científica na América platina setecentista. In: AMANTINO, E. C. D. F.; ENGEMANN, C. (Org.) A Companhia de Jesus na América por seus colégios e fazendas. Rio de Janeiro: Garamond, 2015. p.143-81. GISBERT, T. Iconografia y Mitos Indigenas en el Arte. La Paz, Bolívia: Editorial Gisbert \& Cia, 2008.

GRUZINSKI, S. O pensamento mestiço. São Paulo: Companhia das Letras, 2001.

GUZMÁN, F.; CORTI, P.; PEREIRA, M. Política eclesiástica y circulación de ideas tras las pi nturas murales realizadas durante el siglo XVIII en las iglesias de la Ruta de la Pla- 
ta. HISTORIA, v.II, n.50, p.525-54, julio-diciembre 2017. Disponível em: <http:// revistahistoria.uc.cl/index.php/rhis/article/view/164>. Acesso em: 25 jan. 2019.

JULIO MORAES CONSERVAÇÃO E RESTAURO. Relatório Técnico Parcial de Restauro. Imagens e altares da Capela de São Miguel Arcanjo São Paulo. São Paulo, 20 de setembro de 2010 .

KOK, G. A presença indígena nas capelas da Capitania de São Vicente (Século XVII). Espaço Ameríndio, Porto Alegre, v.5, n.2, p.45-73, out. 2011. Disponível em: <http:// seer.ufrgs.br/index.php/EspacoAmerindio/article/view/19732/13847>. Acesso em: 8 maio 2017.

LEITE, A. S. S. J. História da Companhia de Jesus no Brasil (1938). Belo Horizonte: Itatiaia, 2000. t. VI.

LEME, P. T. de A. P. Notícia Histórica da Expulsão dos Jesuítas do Colégio de São Paulo. RIHGB, Rio de Janeiro, v.12, Tipografia Universal Maemmert, 1849.

Expulsão dos jesuítas e causas que tiveram para ela os paulistas desde o ano de 1611 até o de 1640, em que lançaram fora de toda a capitania de São Paulo e São Vicente. RIHGSP, São Paulo, v.3, 1898.

MARTINS, R. M. de A. Veredas de Luz. A imagem do sol, da lua e das estrelas e a arte dos emblemas nas Missões Jesuíticas, da Amazônia à Argentina. In: MELLO, M. (Org.). Temporalidades. Belo Horizonte, Ed. UFMG. 2019. Belo Horizonte, Ed. UFMG. no prelo.

MONTANARI, T. C. A Capela de São Miguel Arcanjo e suas pinturas parietais: interculturalidade nas artes das missões jesuíticas no estado de São Paulo. In: CONGRESSO INTERNACIONAL DE AMERICANISTAS, 2018, Salamanca, Memoria Del 56. ${ }^{\circ}$ Congreso Internacional De Americanistas v.3 Arte. Salamanca: Ediciones Universidad Salamanca, 2018. p.187-99. Doi: http://dx.doi.org/10.14201/0AQ0251_3. Acesso em: 30 jan. 2019.

- A Capela de São Miguel Arcanjo em São Miguel Paulista: um documento de arquitetura e arte. Campinas, 2019. Dissertação (Mestrado) - Instituto de Filosofia e Ciências Humanas, Universidade Estadual de Campinas.

PARELLADA, C. I. Arte em missões jesuíticas no Guairá (1610-1631): entrelaçando arqueologia, antropologia e arquitetura. In: CONGRESSO INTERNACIONAL DE AMERICANISTAS, 2018, Salamanca, Memoria Del 56. ${ }^{\circ}$ Congreso Internacional De Americanistas v. 3 Arte. Salamanca: Ediciones Universidad Salamanca, 2018. p. 369-78. Doi: http://dx.doi.org/10.14201/0AQ0251_3. Acesso em: 30 jan. 2019.

PETRONE, P. Aldeamentos paulistas. São Paulo: Edusp, 1995.

PLÁ, J. El Barroco Hispano-Guarani. Assunção: Universidad Católica Nuestra Señora de la Assunción; Editora Intercontinental, s. d.

RENDON, J. A. de T. Memória sobre as aldeias de índios da província de S. Paulo, segundo as observações feitas no ano de 1798 - Opinião do autor sobre sua civilização. In: Obras. São Paulo: Governo do Estado, 1978.

RÚA, C. et al. Raman Identification of Pigments in Wall Paintings of the Colonial Period from Bolivian Churches in the Ruta De La Plata. Conservation Science in Cultural Heritage, v.17, p.117-137, mar. 2018. Disponível em: <https://conservation-science. unibo.it/article/view/7945>. Acesso em: 25 jan. 2019. 
SCHAEFER, A. L. P. Estudos analiticos das técnicas e materiais históricos da Igreja Nossa Senhora do Rosário do Embu - Por um plano de conservação. São Paulo, 2000. Tese (Doutorado) - Faculdade de Arquitetura e Urbanismo, Universidade de São Paulo.

SILVA, R. Sobre Taipas e textos: um estudo sobre as narrativas a respeito da cidade de São Paulo. São Paulo: Alameda, 2013.

SIRACUSANO, G. El poder de los colores: de lo material a lo simbólico en las prácticas cuturales andinas: siglos XVI-XVIII. Buenos Aires: Fondo de Cultura Economica, 2005.

SMITH, R. C. A Talha em Portugal. Lisboa: Livros Horizonte, 1962.

TOMASINI, E. et al. Characterization of pigments and binders in a mural painting from the Andean church of San Andrés de Pachama (northernmost of Chile). Heritage Science , v.6, n.61, 2018. Disponível em: <https://heritagesciencejournal.springeropen.com/articles/10.1186/s40494-018-0226-x>. Acesso em: 25 jan. 2019.

RESUMO - A Capela de São Miguel Arcanjo, localizada na zona leste da cidade de São Paulo, apesar de reconhecida por sua peculiar arquitetura em taipa de pilão, teve sua decoração sempre tratada de forma secundária. Em 2007, tal questão passou a ganhar maior destaque em razão das pinturas parietais descobertas durantes os trabalhos de restauro então realizados. A urgência de estudar essas pinturas para orientar um plano de conservação e preservação, contudo, resultou em estudos pouco aprofundados, privilegiando uma visão formalista e eurocêntrica das artes produzidas durante o período colonial. Desse modo, o presente artigo, que se apresenta como um recorte da dissertação de mestrado da autora, busca apresentar uma abordagem não eurocêntrica ao analisar as diversas trocas culturais ocorridas naquele contexto histórico-cultural local e global, ao se basear em documentação primária.

PALAVRAS-CHAVE: Arte colonial, Interculturalidade, Patrimônio cultural, América meridional, São Paulo.

ABSTRACT - The chapel of Saint Michael the Archangel, on the east side of the city of São Paulo, is known for its peculiar rammed earth architecture, but its decoration has always came second. In 2007, this issue became more prominent because of the wall paintings discovered during restoration work carried out that year. The urgent need to study these paintings to guide a conservation and preservation plan, however, resulted in few in-depth studies and the adoption of a formalist and Eurocentric view of the arts produced during the colonial period. Thus, this article, which is an excerpt from the author's Master's dissertation, seeks to present a non-Eurocentric approach to analyze the various cultural exchanges that occurred in that local and global historical-cultural context, based on primary documentation.

KErWORDS: Colonial art, Intercultural exchange, Cultural heritage, South America, São Paulo.

Thais Cristina Montanari é mestra em História, na área de História da Arte pelo Instituto de Filosofia e Ciências Humanas da Universidade Estadual de Campinas (IFCH/ 
Unicamp), com bacharelado e licenciatura em História pela mesma instituição.

@ - thmontanari@gmail.com / https://orcid.org/0000-0003-1327-0037.

Recebido em 15.5.2020 e aceito em 5.3.2021.

I Universidade Estadual de Campinas, Instituto de Filosofia e Ciências Humanas, Campinas, São Paulo, Brasil. 